\title{
Efeitos da Adição de Gesso Agrícola à Cama Aviária sobre o Desempenho de Frangos de Corte
}

\author{
Luís Daniel Giusti Bruno', Vera Maria Barbosa de Moraes ${ }^{2}$, Joji Ariki², Sérgio do Nascimento Kronka ${ }^{3}$
}

\begin{abstract}
RESUMO - O experimento foi realizado para avaliar o efeito da adição de gesso agrícola à cama aviária sobre o desempenho de frangos de corte. Quatro níveis de gesso: G1, G2, G3 e G4 (10, 20, 30 e 40\%, respectivamente, em relação a um grupo controle que usou 50 kg de maravalha de madeira como cama) foram testados. O gesso foi adicionado em diferentes períodos: T1 (quando as aves apresentaram nove dias de idade das aves) e T2 (quantidade total de gesso foi dividida ao meio e aplicada, respectivamente, aos 9 e 23 dias de idade das aves). O delineamento estatístico adotado foi o inteiramente ao acaso, com nove tratamentos, compondo um esquema fatorial 4 x 2 (nível de gesso x idade das aves) + grupo testemunha. Consumo de ração, ganho de peso, conversão alimentar e mortalidade foram avaliados em três períodos: 9 a 21 dias, 21 a 49 dias e 9 a 49 dias de idade das aves. O gesso não influiu no desempenho das aves, exceto no consumo de ração, no primeiro período avaliado ( 9 a 21 dias).
\end{abstract}

Palavras-chave: cama aviária, desempenho, frangos de corte, gesso agrícola

\section{Effects of Agricultural Gypsum Addition to Broiler Litter on Broilers Performance}

\begin{abstract}
The experiment was conducted to evaluate the effect of agricultural gypsum addition to broiler litter on broiler performance. Four levels of gypsum: G1, G2, G3 and G4 (respectively, 10, 20, 30 and 40\% in relation to a control group that used $50 \mathrm{~kg}$ of wood scraps) were tested. The gypsum was added at different periods: T1 (when the broiler presented nine days of age) and T2 (the total amount of gypsum was divided in half and applied, respectively, at the 9 and 23 days of the broiler ages). A completely randomized design was used, with nine treatments, in a 4 x 2 factorial arrangement (level of gypsum $x$ broiler ages) + control group. Feed intake, weight gain, feed:gain ratio and mortality were evaluated in three periods: from 9 to 21, from 21 to 49 , and from 9 to 49 days of the broiler ages. The agricultural gypsum did not affect the broilers performance, except in the feed intake, in the first evaluated period (from 9 to 21 days).
\end{abstract}

Key Words: broiler litter, performance, broilers, agricultural gypsum

\section{Introdução}

É notória, atualmente, a importância da utilização de subprodutos da indústria avícola na suplementação nutricional de animais domésticos, principalmente de ruminantes. A cama de frango é considerada o principal subproduto oriundo da exploração avícola com essa finalidade, devido ao seu valor protéico, à disponibilidade e ao custo, se estes fatores forem comparados às diversas fontes protéicas que fornecem níveis equivalentes de nutrientes a ruminantes. Desse modo, dois problemas que sempre afligiram a indústria avícola e a pecuária bovina podem ser amenizados: o escoamento dos dejetos oriundos de criações de aves e a suplementação nutricional de bovinos, principalmente no período em que as pastagens apresentam baixa produção de forragem.

$\mathrm{O}$ teor de proteína bruta da cama de frango pode variar de acordo com alguns fatores, como o tipo de material utilizado, densidade populacional de criação, tempo de ocupação da cama, entre outros. Devido ao seu baixo custo, tem-se estudado uma metodologia para aumentar o valor protéico da cama com a adição de substâncias ou compostos que, através de reações químicas evitem a perda de nitrogênio da cama, na qual encontra-se sob a forma de amônia $\left(\mathrm{NH}_{3}\right)$, oriundo das excretas das aves.

Uma das maneiras estudadas é a adição de sulfato de cálcio $\left(\mathrm{CaSO}_{4}\right)$, popularmente conhecido como gesso agrícola, e de alguns fosfatos que possivelmente exercem ação inibidora sobre a perda de amônia dos dejetos por volatilização. Entre as substâncias citadas, o gesso agrícola torna-se a melhor opção, devido ao seu baixo custo e alta disponibilidade, facilitando sua aquisição frente aos fosfatos. A reação responsável pelo mecanismo de fixação do nitro-

${ }^{1}$ Aluno do curso de pós-graduação em Zootecnia da FCAV - UNESP, Jaboticabal, SP.

2 Docente do Departamento de Zootecnia da FCAV - UNESP, Jaboticabal, SP.

${ }^{3}$ Docente do Departamento de Ciências Exatas da FCAV - UNESP, Jaboticabal, SP. 
gênio seria $\left(\mathrm{NH}_{4}\right)_{2} \mathrm{CO}_{3}+\mathrm{CaSO}_{4} \rightarrow\left(\mathrm{NH}_{4}\right)_{2} \mathrm{SO}_{4}+$ $\mathrm{CaCO}_{3}$. Entretanto, se ocorrer excesso de gás carbônico, o carbonato de cálcio pode se transformar em carbonato ácido de cálcio, diminuindo a ação inibidora do gesso, ocorrendo a reação $\mathrm{Ca}\left(\mathrm{HCO}_{3}\right)_{2}+$ $\left(\mathrm{NH}_{4}\right)_{2} \mathrm{SO}_{4} \rightarrow \mathrm{CaSO}_{4}+2 \mathrm{NH}_{3}+2 \mathrm{CO}_{2}+2 \mathrm{H}_{2} \mathrm{O}$ (TEUSCHER e ADLER, 1965).

A cama de frango apresenta valores intermediários no que se refere à perda de nitrogênio em relação ao esterco puro de galinhas poedeiras e ao esterco de bovinos em confinamento em mistura com bagaço de cana. O gesso agrícola e alguns fosfatos podem desempenhar a função de inibir a perda de nitrogênio por volatilização da amônia. GLÓRIA et al. (1991), após testar, como inibidores, o superfosfato simples em pó e granulado, gesso agrícola, fosfato parcialmente acidulado e fosfato natural moído, constataram que o mais efetivo na redução de perdas foi o superfosfato simples, tanto em pó como granulado (redução de 58,9\% das perdas), seguido do gesso agrícola (39,3\%), sendo que os outros materiais testados não apresentaram ação. Ao contrário, MALAVOLTA et al. (1979) relataram que a quantidade de gesso a ser adicionada a dejetos de diferentes animais é significativamente menor que a de superfosfato recomendada por TRANI(1981) e KIEHL (1985), levando a crer que o gesso seja mais efetivo na diminuição das perdas de nitrogênio por volatilização.

LON-WO e RODRIGUEZ (1986) verificaram que a utilização de cal, ou seja, óxido de cálcio (substância semelhante ao gesso) e zeólita (designação genérica dos minerais do grupo das zeólitas, silicatos hidratados de alumínio e de um ou mais metais alcalinos ou alcalinos terrosos, mais freqüentemente sódio e cálcio) na cama de frango composta de feno não acarretou diferenças significativas no consumo de ração, no ganho de peso, na conversão alimentar ou peso vivo final das aves. Os autores sugeriram também que o nível de amônia dispersa no ambiente diminuiu, apesar de não mensurado.

Observando a ação de sulfato de cobre (4\%), ácido benzóico (2\%), ácido acético (3\%) e cal hidratada na cama de frango, SOBIH e DOSOKY (1990) constataram que o sulfato de cobre e a cal hidratada mostraram-se mais efetivos, controlando a emissão de amônia (pela fixação do nitrogênio presente nos dejetos) durante 21 dias. Já os ácidos benzóico e acético reduziram os níveis de amônia no ambiente durante 15 e 10 dias, respectivamente.

SINGH et al. (1990) verificaram a eficiência da utilização de cal e formalina, ambos adicionados à camas já usadas, visando o reaproveitamento desta para novos lotes de criação. O crescimento, a conversão alimentar e a mortalidade de aves criadas na cama tratada com a cal, bem como a conversão alimentar ou mortalidade, não diferiram do observado para as aves criadas em maravalha fresca.

Com relação ao efeito do gesso adicionado à cama sobre o desempenho das aves, WYATT e GOODMAN (1992) testaram sua utilização misturando-o com pedra calcária, papel e sílica cristalina. Os tratamentos consistiram de gesso, usado como único constituinte da cama ( $13 \mathrm{~cm}$ de gesso), de gesso utilizado juntamente com raspas de pinheiro $(9 \mathrm{~cm}$ de gesso recobertos por $4 \mathrm{~cm}$ de raspas), sendo os resultados comparados com um tratamento controle composto por $13 \mathrm{~cm}$ de raspas de pinheiro. Não houve diferenças significativas para mortalidade das aves. $\mathrm{O}$ ganho de peso foi significativamente menor aos 21 dias para as aves criadas sobre o gesso, sendo que estas diferenças não se repetiram aos 41 dias. A conversão alimentar não diferiu. Não foram encontradas diferenças entre os tratamentos quanto a contusões e defeitos no peito e anormalidades nas pernas.

O objetivo deste trabalho foi avaliar se a presença do gesso agrícola adicionado à cama apresenta alguma influência sobre o desempenho zootécnico de frangos de corte.

\section{Material e Métodos}

O experimento foi conduzido no Aviário Experimental do Departamento de Zootecnia da Faculdade de Ciências Agrárias e Veterinárias - UNESP - Campus de Jaboticabal, no período de junho a julho de 1996. Foram utilizadas 1440 aves (machos e fêmeas) da linhagem comercial Hubbard, adquiridos com 1 dia de idade e peso médio de 42,5 g, sendo que o experimento teve início quando as aves estavam com 9 dias de idade.

As aves foram criadas em um galpão convencional de alvenaria, com orientação N-S, dividido em 36 boxes experimentais de $1,40 \times 3,20 \mathrm{~m}$, totalizando $4,48 \mathrm{~m}^{2}$ /box, com 40 aves por box. O aquecimento das aves foi realizado com o auxílio de lâmpadas infravermelhas. Foram utilizados comedouros tipo bandeja até 12 dias de idade, ocasião em que foram substituídos por comedouros tubulares. Os bebedouros utilizados eram inicialmente do tipo copo de pressão, sendo substituídos aos nove dias de idade por bebedouros automáticos pendulares. Foi utilizada balança eletrônica para pesagem das aves, bem como da ração fornecida. 


\section{Rev.bras.zootec}

As rações (inicial de 1 a 21 dias, crescimento de 22 a 42 dias e terminação de 43 a 49 dias) foram balanceadas de acordo com as recomendações do "Manual de Manejo Para El Pollo de Engorde Hubbard". As rações foram formuladas à base de milho e farelo de soja, cujas composições dos ingredientes foram obtidas em ROSTAGNO et al. (1987), estando suas composições apresentadas na Tabela 1.

O material escolhido para ser utilizado como cama foi a maravalha ou raspa de madeira, pela sua disponibilidade e por ser o material mais comumente utilizado pelos avicultores em geral.

Quanto aos tratamentos (Tabela 2), para o grupo controle, foram utilizados $50 \mathrm{~kg}$ de maravalha de

Tabela 1 - Composição das rações

Table 1 - Composition of the diets

\begin{tabular}{|c|c|c|c|}
\hline \multirow[t]{3}{*}{$\begin{array}{l}\text { Ingrediente } \\
\text { Ingredient }\end{array}$} & \multicolumn{3}{|c|}{ Ração (\%) } \\
\hline & Inicial & Crescimento & Terminação \\
\hline & Initial & Growing & Finish \\
\hline Milho moído (Ground corn) & 49,19 & 59,85 & 62,02 \\
\hline Farelo de soja (Soybean meal) & 41,26 & 32,09 & 28,55 \\
\hline Óleo degomado (Oil) & 5,44 & 4,26 & 5,52 \\
\hline Fosfato bicálcico (Dicalcium phospate) & 1,95 & 1,65 & 1,45 \\
\hline Calcário calcítico (Limestone) & 1,08 & 1,05 & 1,37 \\
\hline $\operatorname{Sal}($ Salt) & 0,40 & 0,40 & 0,40 \\
\hline DL-Metionina (99\%) (DL-Methionine [99\%]) & 0,17 & 0,19 & 0,18 \\
\hline Suplemento mineral/vitamínico (Vitamin and mineral suplement) ${ }^{1}$ & 0,50 & 0,50 & 0,50 \\
\hline Antioxidante (BHT) (Antioxidant) & 0,01 & 0,01 & 0,01 \\
\hline \multicolumn{4}{|l|}{ Composição calculada } \\
\hline \multicolumn{4}{|l|}{ Calculated composition } \\
\hline Proteína bruta (Crude protein), \% & 23,00 & 20,00 & 18,50 \\
\hline Energia metabolizável, kcal/kg (Metabolizable energy), $\mathrm{kcal} / \mathrm{kg}$ & 3100 & 3150 & 3250 \\
\hline Cálcio (Calcium), \% & 1,00 & 0,90 & 0,90 \\
\hline Fósforo disponível (Available phosphorus), \% & 0,40 & 0,40 & 0,35 \\
\hline Metionina + Cistina (Methionine + Cystine) & 0,89 & 0,83 & 0,78 \\
\hline Lisina (Lysine), \% & 1,11 & 0,99 & 0,96 \\
\hline \multicolumn{4}{|c|}{ 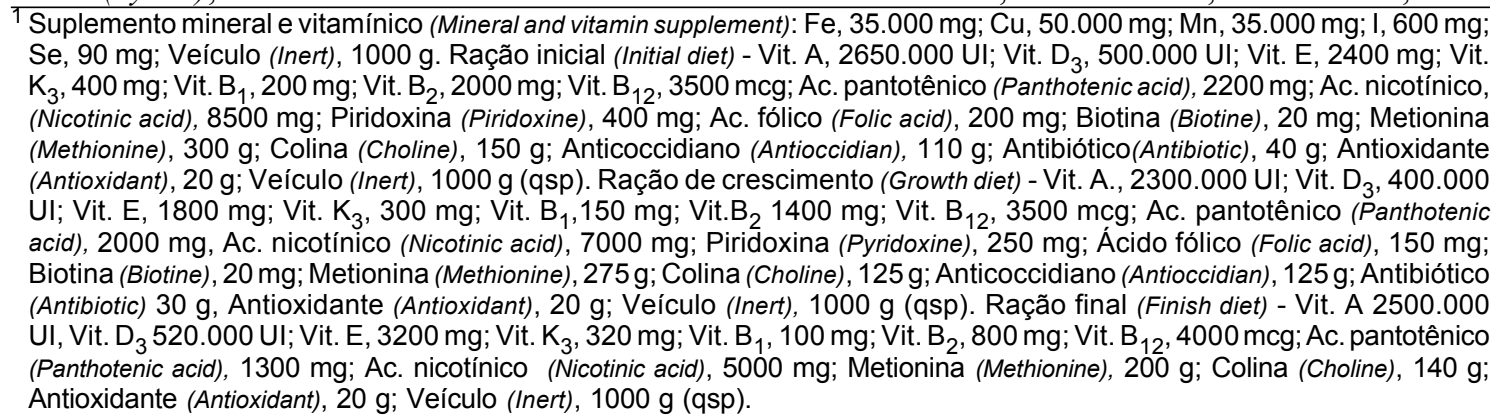 } \\
\hline
\end{tabular}

Tabela 2 - Tratamentos usados

Table 2 - Treatments used

Tratamento Quantidade de gesso + Aplicação do gesso Treatment maravalha(\%)

Amount of gypsum Gypsum application + wood scraps

\begin{tabular}{lcc}
\multicolumn{3}{c}{ cood scraps } \\
\hline 1 & $10+90$ & uma \\
2 & $20+80$ & uma \\
3 & $30+70$ & uma \\
4 & $40+60$ & uma \\
5 & $10+90$ & duas $^{2}$ \\
6 & $20+80$ & duas \\
7 & $30+70$ & duas \\
8 & $40+60$ & duas \\
9 & $100 \%$ de maravalha - controle & - \\
\multicolumn{2}{c}{ 100\% wood scraps - control } & \\
${ }^{1}$ One. & &
\end{tabular}

madeira por parcela experimental e os níveis de gesso foram determinados em função da quantidade de cama: $10,20,30$ e $40 \%$, ou seja, $5 ; 10 ; 15$ e $20 \mathrm{~kg}$ de gesso em cada parcela, com a quantidade completada para $50 \mathrm{~kg}$ com maravalha. Nos tratamentos que consistiram em uma única aplicação, o gesso foi adicionado sobre a cama no início do experimento, sendo incorporado à medida em que a cama era revolvida. Já nos tratamentos com duas aplicações, metade do gesso foi adicionado no início do experimento e a metade restante no $14^{\circ}$ dia do experimento (aves com 23 dias), sendo as incorporações feitas com o revolvimento da cama.

Foi utilizado o delineamento inteiramente ao aca- 
so em esquema fatorial 4 x 2 , sendo quatro níveis de aplicação de gesso e dois períodos de aplicação (aplicação única: aves com 9 dias de idade e duas aplicações: metade da quantidade de gesso total aplicada estando as aves com 9 dias de idade e a metade restante estando as aves com 23 dias de idade) mais um grupo controle, com 40 aves por unidade experimental e quatro repetições, totalizando 36 unidades experimentais. Os resultados foram submetidos à análise estatística seguindo as recomendações de BANZATTO e KRONKA (1989), sendo as médias analisadas pelo teste Tukey (5\%).

$\mathrm{Na}$ condução do experimento foram avaliados os parâmetros consumo de ração, ganho de peso, conversão alimentar e mortalidade.

\section{Resultados e Discussão}

Os resultados de ganho de peso, consumo de ração, conversão alimentar e mortalidade são apresentados nas Tabelas 3, 4 e 5, para os períodos de 9 a 21 dias, 21 a 49 dias e 9 a 49 dias, respectivamente.

De acordo com a Tabela 3 não ocorreram dife- renças significativas para os resultados de ganho de peso, conversão alimentar e mortalidade das aves no período entre 9 e 21 dias. Entretanto, para consumo de ração, o tratamento com $20 \%$ de gesso apontou consumo significativamente menor que o tratamento com $40 \%$, apesar destes dois tratamentos não diferirem de 10 e $30 \%$ de gesso. Esta diferença pode ser atribuída ao fato de as aves terem consumido pequenas quantidades de gesso logo no início do experimento, o que pode ter ocasionado menor consumo de ração. Estes resultados diferem, em parte, dos encontrados por WYATT e GOODMAN (1992), já que estes encontraram diferenças apenas para ganho de peso, que foi significativamente menor aos 21 dias, e não para consumo de ração.

No período entre 21 e 49 dias de idade das aves e no período total do experimento (entre 9 e 49 dias de idade), não houve diferenças significativas nos parâmetros avaliados (Tabelas 4 e 5).

Com relação ao estado geral da cama no final do experimento, não se constataram sinais de emplastamento, evitado talvez pelas seis operações de revolvimento, realizadas no período total do expe-

Tabela 3 - Efeito dos níveis e idade de adição do gesso na cama sobre ganho de peso (GP), consumo de ração $(C R)$, conversão alimentar $(C A)$ e mortalidade $(M)$ no período de 9 a 21 dias de idade

Table 3 - Effect of the gypsum levels and addition ages in broiler litter on weight gain (WG), feed intake $(F I)$, feed:gain ratio (F/G) and mortality (M) from 9 to 21 days of age

\begin{tabular}{|c|c|c|c|c|}
\hline \multirow[t]{2}{*}{ Item } & GP(g) & CR (g) & CA & $\mathrm{M}(\%)$ \\
\hline & $W G$ & & & \\
\hline Testemunha & $511 \mathrm{a}^{1}$ & $722 \mathrm{a}$ & $1,41 \mathrm{a}$ & $0,00 \mathrm{a}^{2}$ \\
\hline \multicolumn{5}{|l|}{ Control group } \\
\hline \multicolumn{5}{|c|}{ Nível de gesso $(\mathrm{G})$} \\
\hline \multicolumn{5}{|c|}{ Gypsum level } \\
\hline Gl & $513 a$ & $705 \mathrm{ab}$ & $1,37 \mathrm{a}$ & $6,36 \mathrm{a}$ \\
\hline G & $525 \mathrm{a}$ & $700 \mathrm{~b}$ & $1,33 \mathrm{a}$ & $6,36 \mathrm{a}$ \\
\hline $\mathrm{G}$ & $519 a$ & 710ab & $1,36 \mathrm{a}$ & $6,36 \mathrm{a}$ \\
\hline GA & $533 \mathrm{a}$ & $728 \mathrm{a}$ & $1,36 \mathrm{a}$ & $7,00 \mathrm{a}$ \\
\hline \multicolumn{5}{|c|}{ Idade de aplicação (I) } \\
\hline \multicolumn{5}{|c|}{ Addition age (I) } \\
\hline Il & $519 \mathrm{a}$ & $710 \mathrm{a}$ & $1,37 \mathrm{a}$ & $6,68 \mathrm{a}$ \\
\hline $\mathrm{I} 2$ & $526 \mathrm{a}$ & $711 \mathrm{a}$ & $1,35 \mathrm{a}$ & $6,36 \mathrm{a}$ \\
\hline \multicolumn{5}{|l|}{ Teste F } \\
\hline \multicolumn{5}{|l|}{ F test } \\
\hline G & 1,59 & $3,79 *$ & 1,35 & 0,23 \\
\hline I & 1,07 & 0,04 & 1,15 & 0,23 \\
\hline GxI & 2,47 & 2,20 & 0,59 & 0,82 \\
\hline CV $(\%)$ & 3,61 & 2,49 & 3,29 & 29,19 \\
\hline
\end{tabular}

* significativo (significant) $(\mathrm{P}<0,05)$.

1 Médias, na coluna, seguidas de letras diferentes são diferentes $(P<0,05)$ pelo teste Tukey.

2 Valores transformados em arc sen $\sqrt{x+1 / 100}$ para análise estatística.

1 Means, within a column, followed by different letters are different $(P<.05)$ by Tukey test.

2 Values transformed in arc sen $\sqrt{x+1 / 100}$ for the statistic analyses. 
Tabela 4 - Efeito dos níveis e idades de adição do gesso na cama sobre ganho de peso (GP), consumo de ração (CR), conversão alimentar (CA) e mortalidade (M) no período de 21 a 49 dias de idade

Table 4 - Effect of the gypsum levels and addition ages in the broiler litter on weight gain (WG), feed intake (FI), feed:gain ratio ( $F: G)$ and mortality $(M)$ from 21 to 49 days of age

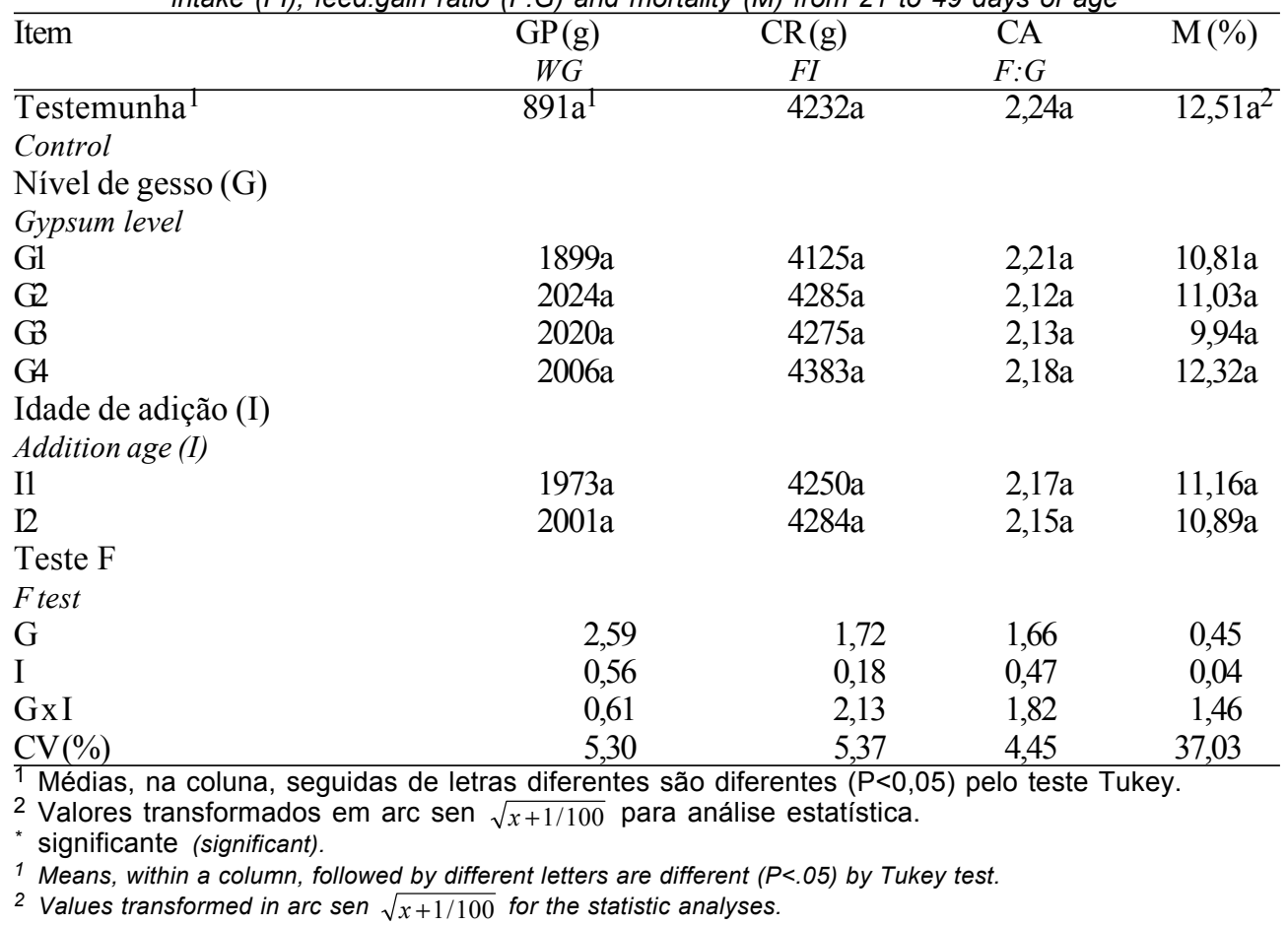

Tabela 5 - Efeito dos níveis e idade de adição do gesso sobre ganho de peso (GP), consumo de ração (CR), conversão alimentar (CA) e mortalidade (M) no período de 9 a 49 dias de idade das aves

Table 5 - Effect of the gypsum levels and addition ages on weight gain (WG), feed intake (FI), feed:gain ratio $(F: G)$ and mortality $(M)$ at 9 and 49 days of age of the birds

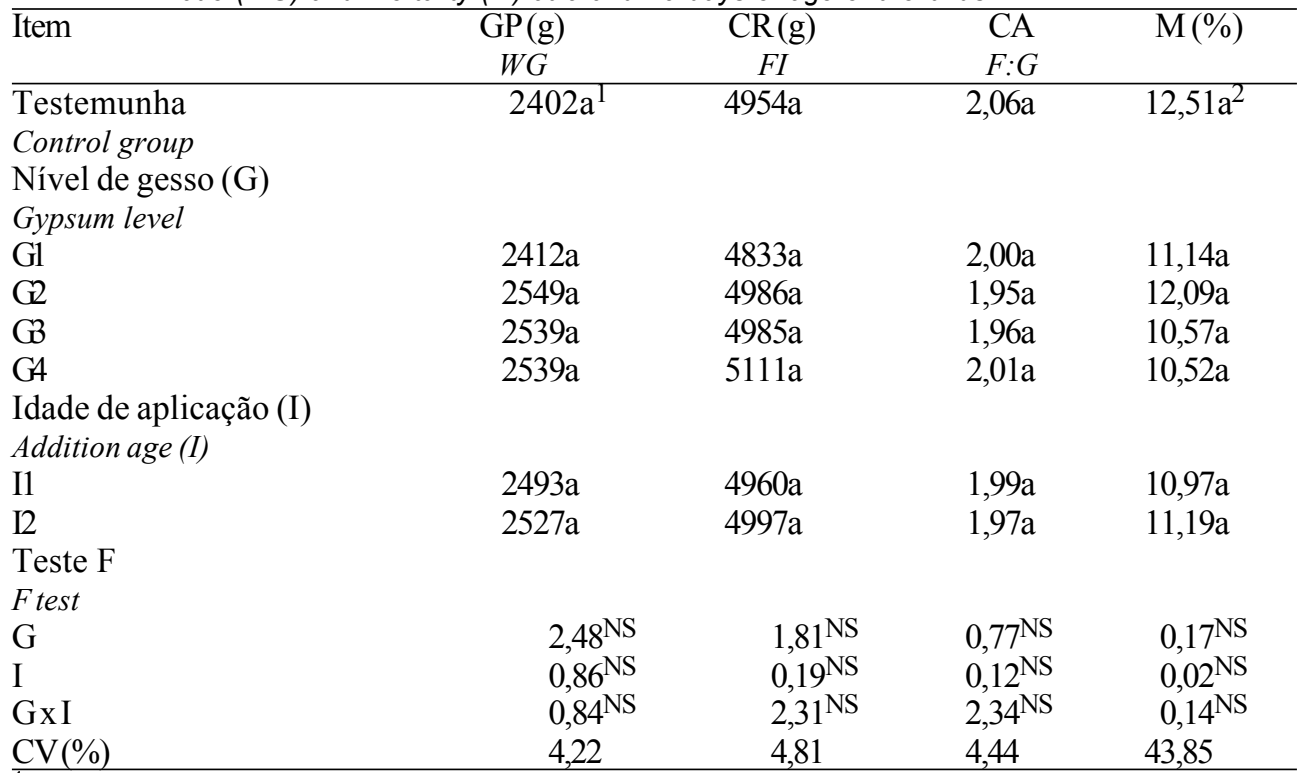

${ }_{1}^{1}$ Médias, na coluna, seguidas de letras diferentes são diferentes $(P<0,05)$ pelo teste Tukey.

2 Valores transformados em arc sen $\sqrt{x+1 / 100}$ para análise estatística.

* significante (significant).

1 Means, within a column, followed by different letters are different $(P<.05)$ by Tukey test.

2 Values transformed in arc sen $\sqrt{x+1 / 100}$ for the statistic analyses. 
rimento. As aves não se apresentaram sujas, em decorrência da presença do gesso na cama, que não causou poeira quando do revolvimento da cama. Apesar de não fazer parte do objetivo do experimento, não foram constatadas lesões ou contusões nos pés e peitos das aves.

\section{Conclusões}

A adição de $20 \%$ de gesso agrícola à cama de frangos de corte causou queda no consumo de ração até os 21 dias de idade, a qual não verificada ao se considerar o ciclo total de criação das aves.

Os diversos níveis de gesso testados não causaram interferência no ganho de peso, na conversão alimentar ou na mortalidade das aves em qualquer momento, não prejudicando, dessa forma, o desempenho zootécnico dos frangos.

O gesso agrícola pode ser utilizado na cama de frango visando futura sua utilização na alimentação de outras espécies, desde que fique comprovado sua eficácia em aumentar o valor nutricional e que não acarrete nenhum gasto adicional ao criador.

\section{Referências Bibliográficas}

BANZATTO, D.A., KRONKA, S.N. 1989. Experimentação agrícola. Jaboticabal: FUNEP, 247p.

GLÓRIA, N.A, BARRETTO, M.C.V., MORAES, C.J. et al. 1991. Avaliação do gesso e de alguns fosfatos como inibidores da volatilização de amônia de estercos. R. Bras. Ciência do Solo, 15(3):297-301.

HUBBARD FARMS. Manual de manejo para el pollo de engorde Hubbard. Sd, 13 p.
KIEHL, E.J. 1985. Fertilizantes orgânicos. São Paulo: Ed. Ceres, $492 \mathrm{p}$.

LON WO, E., RODRIGUEZ, C. 1986. A note on the utilization of zeolite or lime on hay litters for broilers. Cuban J. Agric. Sci., 20(3):259-262.

MALAVOLTA, E., ROMERO, J.P., LIEM, T.H. et al. 1979. Gesso agrícola: seu uso na adubação e correção de solos. São Paulo: Ultrafértil, 31p.

ROSTAGNO, H.S., SILVA, D.J., COSTA, P.M.A. et al. 1987. Composição de alimentos e exigências nutricionais de aves e suínos (Tabelas brasileiras). Viçosa: UFV, 60p.

SINGH, H.P., MISHRA, M., SAHOO, G. et al. 1990. Effect of different methods of treatment of used litter on growth, feed efficiency and economics in broiler production. Ind. J. Prod. Manag., 6(2):109-114.

SOBIH, M.A, DOSOKY, R. 1990. Field trials to reduce ammonia content of air broilers houses. Assiut Vet. Med.J., 24(47):159-164.

TEUSCHER, H., ADLER, R. 1965. El suelo y su fertilidad. Companhia Editorial Continental, 1. ed., 510p.

TRANI, P.E. 1981. Emprego do superfosfato simples com esterco. Campinas: CATI, 5 p. (Instrução prática, 215).

WYATT, C.L., GOODMAN, T.N. 1992. Research note: The utilization of recycled sheetrock (refined gypsum) as a litter material for broilers houses. Poult. Sci., 72(8):1572-1576.

Recebido em: 08/09/97

Aceito em: 07/10/98 